\title{
13
}

\section{Embodiment and Affectivity in Moebius Syndrome and Schizophrenia: A Phenomenological Analysis}

\section{Joel Krueger and Mads Gram Henriksen}

\section{Introduction}

Moebius Syndrome (MS) and schizophrenia may initially seem to have little to do with one another. The former is a rare congenital neurological disorder primarily characterized by bilateral facial paralysis and lateral eye movement incapacity; the latter is a psychotic disorder, typically involving delusion or hallucination, with largely unknown etiology. However, closer examination of the experience of individuals with MS and schizophrenia, respectively, reveals some intriguing points of convergence-along with some important divergences, too. These convergences tend to revolve around the way individuals with MS and schizophrenia experience their embodiment and affectivity.

J. Krueger $(\bowtie)$

University of Exeter, Exeter, Devon, UK

e-mail: J.Krueger@exeter.ac.uk

M.G. Henriksen

University of Copenhagen, Copenhagen, Denmark

(C) The Editor(s) (if applicable) and The Author(s) 2016 
In this comparative study, we examine such experiential manifestations in MS and schizophrenia. We suggest that using phenomenological resources to explore these experiences may help us better understand what it's like to live with these conditions and that such an understanding may have therapeutic value. Additionally, we suggest that this sort of phenomenologically informed comparative analysis of pathological conditions can shed light on the importance of embodiment and affectivity for the constitution of a sense of self and interpersonal relatedness in normal conditions. Such conclusions, we believe, offer important resources for continued research at the intersection of phenomenology and cognitive science in the twenty-first century.

\section{Phenomenological Structures of Embodiment and Affectivity}

Phenomenologists argue that distinctively human forms of thought, perception, and affect are profoundly shaped by both the sort of bodies we have and the things they can do. The body (and its sensorimotor capacities) anchors us in our world and, as we shall see, acts as a mediator enabling the world to appear to us, experientially, in characteristic ways. Phenomenological approaches to the body are particularly interested in articulating the lived structures of embodiment; they are concerned with investigating how various dimensions of embodiment are experienced. This experiential orientation leads phenomenologists to famously distinguish between two dimensions or modes of embodiment: (1) the body through which we pre-reflectively live, that is, the body considered as a subject (Leib); and (2) the body thematically perceived by me and by others, that is, the body considered as an object (Körper). ${ }^{1}$

The body-as-subject refers to the way that embodiment is lived through from the first-person perspective. From this perspective, the body is not something explicitly perceived or reflected on-in the manner, for example, that we might critically scrutinize parts of our body and vow to get more exercise. In the latter case, where the body receives explicit thematic attention, we are concerned with the 
body-as-object. By contrast, the body-as-subject is not really a content of experience but rather a tacit, pre-reflective structure that organizes experience. By 'pre-reflective', phenomenologists simply mean to characterize the manner in which the body is implicitly present as we perceive and act on the world, dynamically shaping both what we experience and how we experience it. In this sense, the body-as-subject, at least when functioning optimally, serves as the transparent medium for experience. $^{2}$

For example, when we see and reach for a mug of coffee on our desk, we don't first consciously locate our arms in space and then intentionally adjust our posture and monitor our movements as we initiate and carry through with the reach. We simply reach for the mug. We're able to spontaneously do so because of the transparent background work of the body-as-subject. Due to ongoing information from proprioceptive and kinaesthetic processes (along with visual and tactile information), we are pre-reflectively aware of the location of our limbs without needing explicitly to attend to our body on a moment-to-moment basis. To use language that will be important later, we enjoy an immediate experiential intimacy with our body and its attendant capacities. Moreover, based upon our spatial position and bodily capacities, we are also aware of what sort of movements and actions are possible within a given space. The body is thus always tacitly present and poised for action. The lived body (or the body-as-subject) in this way serves as our anchored first-person perspective on the world, grounding our egocentric frame of spatial reference by which we are disclosed to ourselves as bodily subjects situated in the world. ${ }^{3}$

But the body-as-subject also shapes experience in another way. When we perceive the coffee mug, we don't simply see it in objective or recognitional terms, say, merely as a thing instantiating different properties such as color, shape, texture, and so on. Rather, the coffee mug is perceptually disclosed as meaningful. An important aspect of our experience is thus to perceive the mug as soliciting a range of potential actions (grasping, picking up, throwing, etc.), specified both by our body's sensorimotor capacities and by the context in which we encounter it (in the kitchen, on the desk in our study, in the dishwasher, etc.). ${ }^{4}$ In this way, the bodyas-subject functions as a transparent constraint on our experience of self 
and world. Although it doesn't show up as an object like other objects in the world, the body-as-subject is nevertheless 'always near me, always there for me', as Merleau-Ponty observes; yet 'it is never really in front of me...it remains marginal to all my perceptions. ${ }^{5}$ Similarly, Sartre writes that 'the body is present in every action although invisible... The body is lived and not known'. ${ }^{6}$

Of course, the body can, and often does, become an object of thematic attention. In contrast to the first-person perspective of the body-assubject, we can adopt a third-person perspective on our body. For example, we can scrutinize individual body parts such as the hand we hold up in front of us or the flabby midsection we gaze at disdainfully in the mirror. Usually, the body-as-subject effaces itself within the fluid performance of world-directed actions - again, it remains in the background, 'marginal to all my perceptions', as Merleau-Ponty puts it-but if something breaks down or goes wrong, our body suddenly moves to the foreground of our attention: for example, if we feel lower back pain while reading at our desk or stumble while reaching for a passing shot during a tennis match. In these cases, we become abruptly aware of our body as a thing impeding our action. Rather than tacitly organizing and enabling experience, it now explicitly disrupts it; when the implicit bodyas-subject becomes explicit (i.e., a thematic object), the usually inhabited or automated bodily processes characterizing the transparent functioning of the body-as-subject become disturbed. ${ }^{7}$

In addition to distinguishing these two modes of embodiment, phenomenologists argue that descriptions of embodied experience are incomplete without a consideration of the way they are mediated by various forms of affect: emotions, moods, and other feeling states. For example, we experience or relate to our body and its capacities differently when tired or anxious, say, in contrast to when we feel energetic or elated. Moreover, these affective dimensions of embodiment shape how the world shows up for us in our experience. Heidegger famously argues that moods are world-disclosing: 'The mood has already disclosed, in every case, Beingin-the-world as a whole, and makes it possible first of all to direct oneself

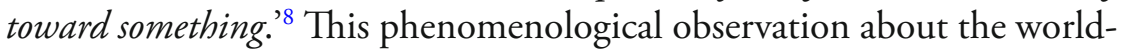
disclosing power of affect is supported by different empirical studies. In one series of studies, subjects were found to estimate the incline of a grade 
to be steeper when wearing a heavy backpack as opposed to not wearing one, or feeling fatigued as opposed to refreshed. ${ }^{\text {P }}$ Another study found that subjects' perception of grade incline is even shaped by psychosocial factors and their associated affects. Individuals judged hills steeper when alone than when in the presence of a supportive partner, or even when simply imagining the presence of a supportive partner. ${ }^{10}$

In sum, phenomenologists argue that basic structures of embodiment and affectivity modulate our experience of self, others, and the world; our bodily presence to self and world is mediated by affectivity. ${ }^{11}$ How this is so-and how these bodily and affective structures, as well as their modulatory effects, may be altered in MS and schizophrenia-will be more apparent in the subsequent analysis. To be clear, in what follows, we do not posit that either the quality of the experience of diminished embodiment and affectivity or the nature of the underlying structural disruptions is identical in MS and schizophrenia. Rather, we suggest that the disruptions of embodiment and affectivity in MS and schizophrenia and their diverse experiential manifestations highlight the importance of these basic structures for the constitution of a sense of self and worldly relatedness also in normal conditions.

\section{Diminished Embodiment and Affectivity in MS and Schizophrenia}

MS is a very rare form of congenital oculofacial paralysis, typically complete and bilateral, resulting from maldevelopment of the sixth and seventh cranial nerves; estimations suggest that MS affects approximately $0.0002-0.002 \%$ of births. ${ }^{12}$ Along with oculofacial paralysis, which leads to atrophy and gives the face a smooth complexion with a slack half-open mouth, individuals with MS also exhibit other abnormalities: abnormal tongue, hypodontia [i.e., missing teeth due to developmental failure (tooth agenesis)], difficulty sucking and eating, limb defects [such as club foot or syndactyly (i.e., abnormal connection of fingers or toes)], and general problems with motor skills, coordination, and balance. ${ }^{13}$ In light of these physical abnormalities, it may seem trivial to characterize MS as involving a disruption of embodiment. However, as we shall see, 
there are subtle phenomenological alterations of embodiment, affectivity, and self-experience in MS that resist an exclusively neurophysiological characterization.

In the case of schizophrenia, phenomenologically informed psychopathologists have long argued that the generative disorder of schizophrenia is a disturbance of the self. This basic intuition was developed more or less explicitly in nearly all foundational texts on the concept of schizophrenia. ${ }^{14}$ For example, Minkowski argued that schizophrenia 'does not originate in the disorders of judgment, perception or will, but in a disturbance of the innermost structure of the self' ${ }^{15}$ Crucially, the 'self' disturbed in schizophrenia does not refer to complex linguistically or conceptually mediated levels of selfhood, such as narrative identity or personhood, but to what has been called the 'minimal self', ${ }^{16}$ 'core self', ${ }^{17}$ or 'ipseity'. ${ }^{18}$ Within the phenomenological tradition, ipseity refers to a fundamental configuration of consciousness, that is, its first-personal givenness; the concept of ipseity strives to capture the implicit sense of coinciding with oneself and one's experiences at any given moment. ${ }^{19}$

For example, when we perceive or reflect upon something, we are implicitly or pre-reflectively aware that we are the ones who perceive or reflect; there is no distance between our experience and ourselves. To put it differently, the self, in this minimal sense (ipseity), is not something prior to or below the flux of experience, somehow linking it together, but a feature of the very manifestation of experience. ${ }^{20}$ This self-presence or self-intimacy usually permeates all our experiential modalities and secures an elusive yet enduring and vital feeling of 'I-me-myself'. In schizophrenia, however, this basic sense of self-intimacy is often threatened or rendered unstable. As Schneider puts it, '[certain] disturbances of self-experience show the greatest degree of schizophrenic specificity. Here we refer to those disturbances of first-personal givenness (Ich-heit) or "mineness" (Meinhaftigkeit)'. ${ }^{21}$ In contemporary phenomenological psychopathology, the disturbance of the self in schizophrenia is most comprehensively articulated in the so-called ipseity disturbance model, ${ }^{22}$ which involves two complementary distortions: diminished self-affection (i.e., attenuated sense of existing as a living subject of awareness and action) and hyper-reflexivity (i.e., exaggerated and alienating forms of self-consciousness). 
During the last two decades, empirical research has consistently documented that certain anomalies of self-experience (i.e., 'self-disorders') aggregate significantly in schizophrenia spectrum disorders but not in other mental disorders. ${ }^{23}$ In brief, self-disorders are non-psychotic, experiential anomalies. They exhibit a trait-like quality, typically date back to childhood or early adolescence, and they tend to persist after remission from a frank psychotic episode. As we shall see, some of these self-disorders reflect alterations in the basic sense of self-presence and embodiment. ${ }^{24}$ Within the phenomenological literature, Stanghellini and Fuchs have argued that an essential feature of schizophrenia is a specific kind of disembodiment. ${ }^{25}$ Stanghellini employs the terms of 'disembodied spirits' and 'deanimated bodies' to describe a peculiar kind of mechanization or objectification of the body-as-subject in schizophrenia. ${ }^{26}$ Fuchs similarly describes a 'disembodiment of the self' in schizophrenia in which the lived body's usual transparency becomes opaque and hinders the patient from inhabiting the body in the usual, unproblematic sense. ${ }^{27}$ On both Stanghellini's and Fuchs's accounts, disembodiment in schizophrenia is intrinsically tied to the basic disturbance of ipseity.

\section{Experiential Manifestations of Diminished Embodiment and Affectivity}

With these phenomenological concepts in place, we will now explore disruptions of embodiment and affectivity in MS and schizophrenia. First, we will consider MS before turning to schizophrenia. Although MS has received considerably less attention than schizophrenia-likely due to its rarity-there are nevertheless sources available that can help highlight experiential dimensions of this condition pertinent to the present discussion.

In a series of books and papers, Jonathan Cole has collected narratives of people living with MS - first-person insights into the subtle alterations of embodiment and affectivity distinctive of this condition..$^{28}$ For our purposes, it is noteworthy that many individuals with MS report persistently experiencing an attenuated sense of their body-as-subject, rather, they appear to predominantly experience their body in a markedly 
impersonal, almost object-like way. This is an especially prominent feature of their early childhood experience. Cole and his co-author Henrietta Spalding (who has MS) seek to capture this type of bodily experience with their notion of the MS subject as 'Cartesian child', ${ }^{29}$ emphasizing how a lack of bodily intimacy, which people with MS often report, may lead to a persistent sense of detachment or alienation from one's own body. For example, James (now in his fifties), describes how this experience has been with him as long as he can remember: 'I have a notion which has stayed with me over much of my life-that it is possible to live in your head; entirely in your head (...) I think there's a lot of dissociation. But I think I get trapped in my mind or my head'. ${ }^{30}$ Another individual, Celia, describes an even more articulated sense of disembodiment, which she claims shaped her fundamental sense of self from a very early age:

I never thought I was a person; I used to think I was a collection of bits. I thought I had all these different doctors looking after all the different bits...'Celia' was not there; that was a name people called the collection of bits. I did not like my feet; I liked my spirit because I was strong as a child. I like my brain... Even though I was a collection of bits I always knew there was something strong inside that I had a mental dialogue with, but it was not the physical body; it was very separate from the physical. ${ }^{31}$

Celia describes here a profound lack of bodily self-intimacy; she regards herself not as a locus of agency and experience but almost as object-like, as a disparate 'collection of bits'. This lack of self-intimacy meant that she never experienced herself as fully immersed in the spontaneous movements, play, and intersubjective reciprocity that are crucial parts of childhood development. ${ }^{32}$ Although this lack of selfintimacy has diminished somewhat in adulthood, it nevertheless seems that Celia still does not have a robust sense of her body-as-subject. She does not experience her body as a fluidly integrated unity-a tacit, smoothly functioning system facilitating her interactions with the world and others. Instead, Celia reports consistently adopting a thirdperson perspective on her own body, including occasions (e.g., gesturing while speaking) when the body would normally recede transparently into the background. 
All my gestures are voluntary, even now aged 46. Everything I do, I think about...All the things I am doing, whether turning my head or moving my hands, is all self-taught. I learnt from observation as an adult... When I was a child, I could not gesture, because I was a collection of bits. My body was not me, so expression in it, with it, would not be from me either. It was not a joined-up feeling. There was a huge bit missing; with the lack of balance, mobility, and problems with coordination, you don't get a sense of self. ${ }^{33}$

Bereft of an enduring sense of bodily self-intimacy and attendant sense of self, Celia thus adopts a hyper-reflective stance toward her body, gestures, and actions. She consciously monitors and pays attention to her body instead of pre-reflectively living through it (as we shall see below, this hyper-reflective stance is reminiscent of some patients with schizophrenia). Others with MS offer similar accounts. For example, James says he's only recently begun using his arms to gesture while speaking-but it continues to be a deliberate, effortful exercise. ${ }^{34}$ Similarly, Lydia says: 'Instead of facial expression I use my hands and shoulders, and my voice, both in its tone and what I say; I construct it all very carefully...I have to monitor these things all the time... None of this is automatic. '35 She reports consciously studying how others gesture and express emotions and then, over time, deliberately incorporating these practices into her own repertoire.

To return to a concept introduced earlier, the phenomenological significance of these first-person accounts is that individuals with MS often feel as though they do not wholly coincide with their lived body, their body-as-subject. Instead, the body is typically related to, or experientially manifest, as an object. And this diminished sense of bodily selfintimacy may be associated with diminished affectivity. Some individuals with MS report feeling a qualitative 'absence' or diminishment in their emotional life. For example, Eleanor says:

[I]f I go back to my late teen years, I was not very embodied as a person and the physical nature of attraction was some way away...At this stage, I did not feel anything [i.e., romantic] physically; even though I had matured physically, I had no feeling. Like the other feelings it had not kicked in. ${ }^{36}$

Along the same lines, James reports that he intellectualizes feelings instead of living in and through them: 'I sort of think happy or I think 
sad, not really saying or recognizing actually feeling happy or feeling sad.' This intellectualizing tendency even includes his experience of falling in love with his wife: 'I think initially I was thinking I was in love with her. It was some time later when I realized that I really felt love. ${ }^{37}$ With respect to his embodied and affective life, he further states: 'I've often thought of myself as a spectator rather than as a participant.' ${ }^{38}$ Finally, Celia describes similar emotional experience dating back to childhood: 'I did not express emotion. I am not sure that I felt emotion, as a defined concept. At my birthday parties I did not get excited. There were people around excited, but I followed what they did. '39 She continues: 'I don't think I was happy, or even had the concept of, happiness as a child. I was saddened by being in pain or having horrid things like a blood test. ${ }^{30}$ Surely Celia was capable of feeling some emotion. What these quotes appear to suggest, rather, is not an utter absence of emotion but more likely a restricted range of emotional sensitivity, responsivity, and expressivity. ${ }^{41}$

In sum, we have seen that individuals with MS often experience a diminished sense of embodiment, which is consequential of but, in our view, not reducible to their specific physiological abnormalities. In other words, the typically persistent and pervasive lack of bodily self-intimacy does not pertain exclusively to, as might be predicted, oculofacial paralysis but to a more general overall feeling of being disconnected and at a distance from one's body-as-subject. Invariably, this experiential distance entails a feeling of bodily self-alienation (variously reflected in complaints such as feeling 'trapped in my mind or my head', 'separation from the physical body', 'collection of bits', etc.) and, at least in the cases we have discussed, an interdependent, observational, or self-monitoring stance toward one's own body, agency, and gestures as objects, which may further increase feelings of alienation. This experiential distance can also affect the individuals' emotional life to the extent that emotions appear as if 'absent' (as in the case of Eleanor) or only accessible through reflection or 'intellectualization' (as in the case of James) rather than pre-reflectively felt and lived through. In our view, these forms of diminished embodiment and affectivity, which revolve around disruptions of the usually taken-for-granted and implicit processes of the body-as-subject are central to the experience of being disconnected from oneself in MS (reflected 
in statements such as 'being a spectator to rather than as a participant in one's own life', 'not feeling like a person', 'lacking a sense of self', etc.).

We now turn to schizophrenia. As we shall see, there are certain illuminating similarities between experiences of diminished embodiment and affectivity in MS and schizophrenia. However, when unraveling the phenomenological complexities of these experiences and their embeddedness in the underlying psychopathological Gestalt of schizophrenia, some crucial differences come to light, gravitating especially around disturbances of ipseity.

Many patients with schizophrenia spectrum disorders experience problems with their embodiment. For example, 'K', 25 years old, describes a complicated relationship with her own body:

I have always had a difficult relation to my body (...) It's as if there is a distance between my body and my mind. It's like my mind is a little puppeteer, sitting far away, controlling my body. It's not like I see myself from above or something. But it's like I'm not in my body or not attached to it. It's like my body is an appendix that hangs below me. My body feels alien to me (...) I wish I could be free of it. ${ }^{42}$

Here, ' $\mathrm{K}$ ' describes phenomena that in the clinical, self-disordersoriented research literature are called 'psycho-physical split', referring to the experience as if the mind and the body somehow do not fit together or are disconnected, and 'somatic depersonalization', referring to the experience of perceiving one's own body or parts of it as strange, alien, disconnected, and so on. When ' $\mathrm{K}$ ' describes her mind as a 'puppeteer', she is not describing an out-of-body experience ('It's not like I see myself from above or something'). Rather, she is conveying an experience of not feeling truly present in her body and alienated from it ('it's like I'm not in my body or not attached to it'; 'My body feels alien to me'). Such experiences are quite common in schizophrenia spectrum disorders, though their specific quality and articulation may vary-for example, 'the body feels awkward as if it does not really fit. It feels like the body is not really me, as if it is rather a machine controlled by my brain', ${ }^{43}$ or 'I feel strange, I am no longer in my body, it is someone else; I sense my body but it is far away, some other place. ${ }^{34}$ In schizophrenia, diminished embodiment 
may take on an alien or quasi-mechanical character: 'I'm blessed with a bladder-emptier that I can turn on and off, and an anal expeller', ${ }^{45}$ or 'I'm a psycho-machine'. ${ }^{46}$ For Peter, 18 years old, his initial, non-psychotic experiences of psycho-physical split, somatic depersonalization, and loss of control of bodily movements evolved into vague ideas about external influence ('it sometimes feels as if someone else is performing my actions. It's as if it's not me. I feel like a puppet') and eventually into psychosis with delusions of control. ${ }^{47}$

Most importantly, the unstable self-presence or self-intimacy in schizophrenia is not restricted to the bodily domain but is also often pervasively manifest in other modalities of consciousness (thinking, perceiving, feeling, etc.). For example, Peter describes persistent feelings of not being fully present in the world: 'It's as if I'm inside a glass dome (...) everything seems so far away as if there is an invisible wall I cannot penetrate. ${ }^{38}$ Experiences of 'diminished presence', which also are manifestations of the disturbance of ipseity, often entail a felt distance toward the world and may involve a decreased capacity to become affected, touched, or moved by others or events and to emotionally respond to such stimulations. This is the case for Peter, who states: 'I don't truly feel the world, because I don't feel anything inside'; he refers to the world as a 'dream world' and himself as a 'zombie' or 'a shell devoid of emotions'. ${ }^{49}$ Such experiences typically affect the spontaneous immersion in the shared social world and the ability to interact with others in a smooth, fluid, and contextsensitive manner. The failing sense of self-presence may also be associated with an experience of not being fully awake, as if the very luminosity of consciousness was somehow diminished-for example, 'I am only $70 \%$ conscious ${ }^{50}$; 'I feel a sort of emptiness in my head as if I am not awake. I feel detached or airy as if I am not present' ${ }^{51}$; 'My consciousness is not as whole as it should be'; 'I am half-awake. ${ }^{52}$

Furthermore, many patients with incipient schizophrenia describe a variety of interdependent cognitive disturbances. Some of these are worth highlighting here because they indicate important differences between schizophrenia and MS, which should not to be overlooked. For example, some (but not all) thoughts, typically with a neutral or trivial content, may appear somehow alien or anonymous to the patient as if he himself has not generated them ('my thoughts feel strange as if they aren't really 
coming from me'). 53 'Thought pressure', that is, the experience of having many thematically unrelated thoughts or trains of thought occurring simultaneously or immediately after each other, with a loss of meaning, is another frequently found experience in schizophrenia spectrum disorders; one patient described this experience with the analogy of 'rockets shooting in all directions at once. It's one big chaos'. ${ }^{54}$ 'Thought pressure' may be linked to 'spatialization' of thoughts, that is, an anomalous experience of thoughts not as subjectively lived through but rather as quasi-objective things, for example, localized to specific parts of the brain, physically moving around inside the head or pressing on the inside of the skull. Patients also often report listening to their own thoughts spoken aloud internally with they own voice or reading their own thoughts as if they were subtitles on a film. In brief, these various experiences testify to the fact that the unstable sense of self-presence or self-intimacy in schizophrenia transcends beyond the bodily and affective dimensions into other modalities of consciousness, which, by contrast, appear unaffected in MS (e.g., cognition, perception).

Finally, we will return to ' $\mathrm{K}$ ' and briefly discuss some of the problems she encounters when interacting with others:

I always feel that it is like enormously feigned when I have some social interaction. It feels false, like I can't react naturally or sincerely like everyone else... I have the experience that there are two of me: the one that interacts with someone and then there is the real me, who sits there behind. For example, 'I sense that the one I'm talking to finds my statement a little transgressive, so I add a little humour here to establish an ironic distance. That may perhaps... yes, that worked well...' And I do it, like, simultaneously. I don't feel present at all. ${ }^{55}$

Here, ' $K$ ' describes hyper-reflectivity that takes the form of an excessive self-monitoring, operating alongside her social interaction and compromising her sense of being present in social situations. With regard to certain aspects (e.g., hyper-reflection, self-monitoring), her description may appear similar to those of patients with MS (e.g., Henrietta's and Lydia's similar reports of self-consciously monitoring every gesture and movement when interacting with others). However, we should not fail to notice the underlying schizophrenic vulnerability that is also indicated in 
this vignette (e.g., 'I have the experience that there are two of me'), which clearly distinguishes ' $\mathrm{K}$ 's' difficulties from those of patients with MS. Her feeling of social interactions being 'false' and of not being able to 'react naturally or sincerely like everyone else' is deeply rooted in her persistent feeling of not being truly human, which dates to early childhood-'I feel like I'm not a natural human being or a proper human being or something like that.' ${ }^{56}$ The unsettling feeling of being radically, yet often ineffably, different from others is very common in schizophrenia and typically at the very heart of the patient's suffering.

In sum, we have discussed various clinical examples of diminished embodiment and affectivity in schizophrenia that gravitate around disruptions of the first-personal articulation of experience. As we have seen, the ipseity disturbance gives rise to a multiplicity of interconnected and mutually implicative anomalous self-experiences that threatens one's most intimate, foundational sense of self and enables a radical form of self-alienation to grow from within the disturbed subjectivity, potentially resulting in psychotic experiences of being controlled by an external force, persecuted or addressed by a hallucinatory other.

\section{Conclusion}

On a surface level, we found similarities among experiences of diminished embodiment and affectivity in MS and schizophrenia, respectively. These include hyper-reflection, self-monitoring, and profound bodily selfalienation, characterized by a pervasive tendency in both MS and schizophrenia to experience and relate to the lived body (i.e., bodyas-subject) primarily as an object. In both MS and schizophrenia, the body-as-subject's transparency - the tacit, mediating processes enabling it to function smoothly and unobtrusively in the world-appear disrupted. Although the origin and nature of these disruptions are very different in the two conditions, in both cases the body and it capacities are no longer simply inhabited or pre-reflectively lived through but rather explicated in a concrete, objectifying, and alienating manner. Notably, we also found crucial differences between experiences of diminished embodiment and 
affectivity in MS and schizophrenia, reflecting the different underlying pathologies.

Our study lends support to phenomenologists' claims concerning the importance of embodiment, affectivity, and intercorporeity (or embodied intersubjectivity) for the constitution of a sense of self in abnormal as well as normal conditions. For phenomenologists, the fluid oscillation between the body-as-subject and the body-as-object highlights a 'bodily ambiguity' at the heart of our embodied experience: as embodied subjects, we are neither wholly subjects nor wholly objects, but somehow always both. Looking at cases where this ambiguity is disrupted, and the cascade of anomalous experiences such disruptions may entail, points to the constitutive role this bodily ambiguity plays in shaping our general way of inhabiting, experiencing, and engaging with the world.

Finally, we suggest that utilizing phenomenological resources to address experiences of diminished embodiment and affectivity in MS and schizophrenia may enable us to better understand what it sometimes is like to live with these conditions and potentially offer targets for future research and therapeutic intervention. As phenomenology and cognitive science continue to intersect in the twenty-first century, new interventions become possible in light of our research here. For example, interventions striving to enforce the individuals' experience of embodiment could easily be included as part of the treatment in both MS and schizophrenia. In the case of MS, interventions designed to help individuals with MS develop alternative embodied communication strategies (e.g., gestures) to compensate for their lack of facial expressivity seem relevant. ${ }^{57}$ In the case of schizophrenia, interventions designed to strengthen the patient's unstable or wavering sense of self-presence or ipseity are strongly needed.

\section{Notes}

1. Edmund Husserl, Ideas Pertaining to a Pure Phenomenology and to a Phenomenological Philosophy-Second Book: Studies in the Phenomenology of Constitution, trans. R. Rojcewicz and A. Schuwer (Dordrecht: Kluwer Academic Publishers, 1989); Maurice Merleau-Ponty, The Phenomenology of 
Perception (London: Routledge, 2002); cf. Carman, Taylor, 'The Body in Husserl and Merleau-Ponty'. Philosophical Topics 27, no. 2 (1999): 205-26.

2. Shaun Gallagher, How the Body Shapes the Mind (Oxford and New York: Clarendon Press, 2005).

3. Dorothée Legrand, Claudio Brozzoli, Yves Rossetti, and Alessandro Farnè, 'Close to Me: Multisensory Space Representations for Action and PreReflexive Consciousness of Oneself-in-the-World'. Consciousness and Cognition 16, no. 3 (2007): 687-99. doi:10.1016/j.concog.2007.06.003.

4. James J. Gibson, The Ecological Approach to Visual Perception (Hillsdale: Lawrence Erlbaum Associates, 1979).

5. Merleau-Ponty, Phenomenology of Perception, p. 104.

6. Jean-Paul Sartre, Being and Nothingness, trans. Hazel E. Barnes (New York: Washington Square Press, 1956), p. 427.

7. Thomas Fuchs, 'Corporealized and Disembodied Minds: A Phenomenological View of the Body in Melancholia and Schizophrenia', Philosophy, Psychiatry, \& Psychology 12, no. 2 (2005): 95-107.

8. Martin Heidegger, Being and Time, trans. John Macquarrie and Edward Robinson (New York: Harper \& Row Publishers, 1962), p. 176.

9. Dennis R. Proffitt, Mukul Bhalla, Rich Gossweiler, and Jonathan Midgett, 'Perceiving Geographical Slant', Psychonomic Bulletin \& Review 2, no. 4 (1995): 409-28. doi:10.3758/BF03210980; D.R. Proffitt, S.H. Creem, and W.D. Zosh, 'Seeing Mountains in Mole Hills: Geographical-Slant Perception', Psychological Science 12, no. 5 (2001): 418-23.

10. Simone Schnall, Kent D. Harber, Jeanine K. Stefanucci, and Dennis R. Proffitt, 'Social Support and the Perception of Geographical Slant', Journal of Experimental Social Psychology 44, no. 5 (2008): 1246-55. doi:10.1016/j.jesp.2008.04.011.

11. Giovanna Colombetti, The Feeling Body: Affective Science Meets the Enactive Mind (Cambridge, MA: MIT Press, 2014); Matthew Ratcliffe, Feelings of Being: Phenomenology, Psychiatry and the Sense of Reality. 1st ed. (New York: Oxford University Press, USA, 2008); G. Stanghellini and R. Rosfort, Emotions and Personhood, Exploring Fragility, Making Sense of Vulnerability (Oxford: Oxford University Press, 2013).

12. M. Kuklík, 'Poland-Mobius Syndrome and Disruption Spectrum Affecting the Face and Extremities: A Review Paper and Presentation of Five Cases', Acta Chirurgiae Plasticae 42, no. 3 (2000): 95-103; Harriette T.F.M. Verzijl, Bert van der Zwaag, Johannes R.M. Cruysberg, and George W. Padberg, 'Mobius Syndrome Redefined: A Syndrome of Rhombencephalic Maldevelopment', Neurology 61, no. 3 (2003): 327-33. 
13. Marilyn T. Miller and Kerstin Strömland, 'The Möbius Sequence: A Relook', Journal of American Association for Pediatric Ophthalmology and Strabismus 3, no. 4 (1999): 199-208.

14. For example, see E. Bleuler, Dementia praecox or the group of schizophrenias, trans. J. Zinkin (New York: International Universities, 1950 [1911]); Karl Jaspers, General Psychopathology, trans. J. Hoenig and Marian W. Hamilton (Baltimore, MD: Johns Hopkins University Press, 1997 [1913]); J. Berze, Die primäre Insuffizienz der psychischen Aktivität. Ihr Wesen, ihre Erscheinungen und ihre Bedeutung als Grundstörungen der Dementia Praecox und der Hypophrenen überhaupt (Leipzig: Frank Deuticke, 1914); Eugène Minkowski, La Schizophrénie: Psychopathologie des Schizoïdes et des Schizophrènes (Paris: Payot, 1927); K. Schneider, Clinical Psychopathology, trans. M.W. Hamilton (New York: Grune \& Stratton, 1959 [1950]).

15. Eugène Minkowski, Au-delà du rationalisme morbide (Paris: L'Harmattan, 1997), p. 114.

16. Dan Zahavi, Subjectivity and Selfhood: Investigating the First-Person Perspective (Cambridge, MA: MIT Press, 2005).

17. A.R. Damasio, Self Comes to Mind: Constructing the Conscious Brain (New York, NY: Pantheon Books, 2010).

18. Louis A. Sass and Josef Parnas, 'Schizophrenia, Consciousness, and the Self', Schizophrenia Bulletin 29, no. 3 (2003): 427-44.

19. Sass and Parnas, 'Schizophrenia, Consciousness, and the Self'.

20. Michel Henry, The Essence of Manifestation, trans. Gerard Etzkorn (The Hague: Martinus Nijhoff, 1973).

21. Schneider, Clinical Psychopathology, p. 58; quoted in J. Parnas and M.G. Henriksen, 'Disordered self in the schizophrenia spectrum: A clinical and research perspective', Harvard Review of Psychiatry 22 (2014):251-265, p. 252.

22. Sass and Parnas, 'Schizophrenia, Consciousness, and the Self'.

23. For a review, see Parnas and Henriksen, 'Disordered self in the schizophrenia spectrum'.

24. Vide infra; cf. J. Parnas and P. Handest, 'Phenomenology of Anomalous Experiences in Early Schizophrenia'. Comprehensive Psychiatry 44 (2013): 121-34; Sass and Parnas, 'Schizophrenia, Consciousness, and the Self'; J. Parnas, P. Møller, T. Kircher, et al. 'EASE: Examination of Anomalous Self-Experience'. Psychopathology 38 (2005): 236-58; M.G. Henriksen and J. Parnas, 'Clinical manifestations of self-disorders and the Gestalt of schizophrenia', Schizophrenia Bulletin 38 (2012): 657-60. 
25. G. Stanghellini, Disembodied Spirits and Deanimated Bodies: The Psychopathology of Common Sense (1st ed.) (Oxford and New York: Oxford University Press, USA, 2004); 'Embodiment and Schizophrenia', World Psychiatry 8, no. 1 (2009): 56-9; Fuchs, 'Corporealized and Disembodied Minds'.

26. Stanghellini, Disembodied Spirits and Deanimated Bodies.

27. Fuchs, 'Corporealized and Disembodied Minds'.

28. For example, see Jonathan Cole, 'On Being Faceless: Selfhood and Facial Embodiment'. Journal of Consciousness Studies 4, no. 5-6 (1997): 467-84; About Face (Cambridge, MA: MIT Press, 1998); 2008. 'The Role of the Face in Intersubjectivity, Emotional Communication and Emotional Experience; Lessons from Moebius Syndrome', in Enacting Intersubjectivity: A Cognitive and Social Perspective on the Study of Interactions, eds. F. Morganti, A. Carassa, G. Riva (Amsterdam: IOS Press, 2008), pp. 237-49; 'Intimacy; Views from Impairment and Neuroscience'. Emotion, Space and Society 13 (November, 2014): 87-94. doi:10.1016/j.emospa.2014.01.001.

29. Jonathan Cole and Henrietta Spalding, The Invisible Smile: Living without Facial Expression (Oxford: Oxford University Press, 2009), p. 41.

30. Cole and Spalding, The Invisible Smile, p. 68, 72.

31. Cole and Spalding, The Invisible Smile, p. 42.

32. Cole and Spalding, The Invisible Smile, p. 56; cf. Colwyn Trevarthen, 'The Self Born in Intersubjectivity: The Psychology of an Infant Communicating', in The Perceived Self, ed. U. Neisser (Cambridge: Cambridge University Press, 1993), pp. 121-73.

33. Cole and Spalding, The Invisible Smile, p. 190; emphasis added.

34. Cole and Spalding, The Invisible Smile, p. 74.

35. Cole and Spalding, The Invisible Smile, p. 152.

36. Cole and Spalding, The Invisible Smile, pp. 169-70.

37. Cole and Spalding, The Invisible Smile, p. 72, 70.

38. Cole and Spalding, The Invisible Smile, p.72.

39. Cole, About Face, p. 244.

40. Cole, About Face, p. 244.

41. Joel Krueger and John Michael, 'Gestural Coupling and Social Cognition: Möbius Syndrome as a Case Study', Frontiers in Human Neuroscience 6, no. 81 (2012): 1-14, doi:10.3389/fnhum.2012.00081; cf. J. Krueger, 'Dewey's Rejection of the Emotion/Expression Distinction', in Neuroscience, Neurophilosophy, and Pragmatism: Brains at Work in the World, eds. T. Solymosi and J.R. Shook (New York: Palgrave Macmillan, 2014), pp. 140-61. 
42. M.G. Henriksen and J. Nordgaard, 'Self-disorders in Schizophrenia', in An Experiential Approach to Psychopathology - Phenomenology of Psychotic Experiences, ed. G. Stanghellini and M. Aragona (Springer, NY, forthcoming).

43. M.G. Henriksen and J. Nordgaard, 'Schizophrenia as a Disorder of the Self', Journal of Psychopathology 20 (2014): 435-41, p. 437.

44. Parnas and Handest, 'Schizophrenia, Consciousness, and the Self', p. 127.

45. A. Angyal, 'The Experience of the Body-Self in Schizophrenia', Archives of Neurology \& Psychiatry 35 (1936): 1029-53.

46. B. Kimura, 'Cogito and I: A Bio-logical Approach'. Philosophy, Psychiatry, \& Psychology 8, no. 4 (2001): 331-336. These reports are reminiscent of Celia's earlier description of experiencing herself in childhood as 'a collection of bits', each with their own function.

47. Henriksen and Parnas, 'Clinical manifestations of self-disorders and the Gestalt of schizophrenia', p. 659.

48. Henriksen and Parnas, 'Clinical manifestations of self-disorders and the Gestalt of schizophrenia', p. 658.

49. Henriksen and Parnas, 'Clinical manifestations of self-disorders and the Gestalt of schizophrenia', p. 659.

50. M. Cermolacce, J. Naudin, and J. Parnas, "The "minimal self" in psychopathology: Re-examining the self-disorders in the schizophrenia spectrum,' Consciousness and Cognition 16 (2007): 703-14, p. 706.

51. M.G. Henriksen, A. Raballo, and J. Parnas, 'The pathogenesis of auditory verbal hallucinations in schizophrenia: a clinical-phenomenological account'. Philosophy, Psychiatry, \& Psychology (forthcoming).

52. Parnas and Handest, 'Schizophrenia, Consciousness, and the Self', p. 125.

53. Henriksen and Nordgaard, 'Schizophrenia as a Disorder of the Self', p. $436 f$.

54. Henriksen and Nordgaard, 'Schizophrenia as a Disorder of the Self', p. 437.

55. Henriksen and Nordgaard, 'Self-disorders in Schizophrenia'.

56. Henriksen and Nordgaard, 'Self-disorders in Schizophrenia'.

57. For example, see J. Michael, K. Bogart, K. Tylen, J. Krueger, M. Bech, J.R. Ostergaard, and R. Fusaroli, 'Training in Compensatory Strategies Enhances Rapport in Interactions Involving People with Moebius Syndrome', Frontiers in Neurology, 6, no. 213 (2015): 1-11. 